\title{
Surveillance of genetic markers associated with Plasmodium falciparum resistance to artemisinin- based combination therapy in Pakistan, 2018-2019
}

\author{
Abdul Qader Khan \\ Kohat University of Science and Technology \\ Leyre Pernaute-Lau \\ Karolinska Institutet \\ Aamer Ali Khattak \\ University of Haripur \\ Sanna Luijcx \\ Karolinska Institutet

\section{Berit Aydin-Schmidt} \\ Karolinska Institutet \\ Mubashir Hussain \\ Kohat University of Science and Technology \\ Taj Ali Khan \\ Kohat University of Science and Technology

\section{Farees Uddin Mufti} \\ Quaid-i-Azam University \\ Ulrika Morris ( ulrika.morris@ki.se) \\ https://orcid.org/0000-0003-4734-5754
}

\section{Research}

Keywords: Plasmodium falciparum, Pakistan, Artemisinin-based combination therapy, artemetherlumefantrine, chloroquine, drug resistance, P. falciparum coronin, P. falciparum kelch 13 propeller domain, pfcrt, pfmdr1

Posted Date: March 6th, 2020

DOI: https://doi.org/10.21203/rs.3.rs-16248/v1

License: (c) (1) This work is licensed under a Creative Commons Attribution 4.0 International License. Read Full License 
Version of Record: A version of this preprint was published at Malaria Journal on June 8th, 2020. See the published version at https://doi.org/10.1186/s12936-020-03276-8. 


\section{Abstract}

Background: The spread of artemisinin resistance in the Greater Mekong Subregion of Southeast Asia poses a significant threat for current anti-malarial treatment guidelines globally. The aim of this study was to assess the current prevalence of molecular markers of drug resistance in Plasmodium falciparum in the four provinces with the highest malaria burden in Pakistan, after introducing artemether-lumefantrine as first line treatment in 2017.

Methods: Samples were collected during routine malaria surveillance in Punjab, Sindh, Baluchistan, and Khyber Pakhtunkhwa provinces of Pakistan between January 2018 and February 2019. P. falciparum infections were confirmed by rapid diagnostic test or microscopy. P. falciparum positive isolates $(n=179)$ were screened by Sanger sequencing for single nucleotide polymorphisms (SNPs) in the $P$. falciparum kelch 13 (pfk13) propeller domain and in P. falciparum coronin (pfcoronin). SNPs in $P$. falciparum multidrug resistance 1 (pfmdr1) N86Y, Y184F, D1246Y and $P$. falciparum chloroquine resistance transporter (pfcrt) K76T were genotyped by PCR-restriction fragment length polymorphism.

Results: No artemisinin resistance associated SNPs were identified in the pfk13 propeller domain or in pfcoronin. The pfmdr1 N86, 184F, D1246 and pfcrt K76 alleles associated with reduced lumefantrine sensitivity were present in $83.8 \%$ (150/179), 16.9\% (29/172), 100.0\% (173/173), and 8.4\% (15/179) of all infections, respectively. The chloroquine resistance associated pfcrt $76 \mathrm{~T}$ allele was present in $98.3 \%$ $(176 / 179)$ of infections.

Conclusion: This study provides an update on the current prevalence of molecular markers associated with reduced sensitivity to artemether and/or lumefantrine in $P$. falciparum, including a first baseline assessment of polymorphisms in pfcoronin. No mutations associated with artemisinin resistance were observed in $p f k 13$ or pfcoronin. However, the prevalence of the pfmdr1 N86 and D1246 alleles, that have been associated with decreased susceptibility to lumefantrine, remain high. Although clinical and molecular data suggest that the current malaria treatment guideline for $P$. falciparum are presently effective in Pakistan, close monitoring for artemisinin and lumefantrine resistance will be critical to ensure early detection and enhanced containment of emerging ACT resistance spreading across from Southeast Asia.

\section{Background}

In spite of ongoing global efforts to control and eradicate malaria, the disease remains a significant contributor to morbidity and mortality worldwide. According to the World Health Organization (WHO), there were over 228 million cases of malaria in 2018, resulting in approximately 405,000 deaths [1]. In Pakistan, malaria transmission is moderate, with approximately $60 \%$ of the population ( 123 million people) at high risk of contracting malaria. According to the Pakistan malaria annual report there were more than 300,000 confirmed malaria cases reported in 2018 [2]. Among these cases, 84\% were caused by Plasmodium vivax, $15 \%$ by Plasmodium falciparum, and $1 \%$ were mixed P. falciparum and P. vivax infections.

Malaria control relies on a handful of interventions including prompt and effective treatment with artemisinin-based combination therapy (ACT); a strategy currently threatened by P. falciparum resistance to 
artemisinin and its partner drugs spreading across Southeast Asia [3, 4]. Artemisinin resistance was first reported in Cambodia in 2009 [5, 6], and is now widespread across the Greater Mekong Subregion [4, 7, 8]. It is phenotypically characterized by delayed parasite clearance following treatment, which has been associated with a number of single nucleotide polymorphisms (SNPs), including F446I, Y493H, R539T, I543T, and C580Y, in the propeller domain of the P. falciparum kelch 13 (pfk13) gene $[4,9,10]$. Possible independent emergence of the pfk13 C580Y mutation has been reported in Guyana [11] and Papua New Guinea [12], and candidate pfk13 resistance mutations (P574L and A675V), which are common in southeast Asia and associated with delayed parasite clearance, have been identified in Rwanda [13]. Concomitant emergence of tolerance and/or resistance to the long-acting partner drugs in ACTs (namely, piperaquine, mefloquine, sulfadoxine-pyrimethamine, lumefantrine, and amodiaquine), has resulted in ACT treatment failures in several areas of southeast Asia [3,14-16]. Recently, delayed parasite clearance associated with polymorphisms in pfk13 has been reported in Eastern India after treatment with artesunate-sulfadoxinepyrimethamine (AS + SP) $[17,18]$.

The availability of molecular markers for both artemisinin- and partner drug resistance has greatly aided close surveillance of the emergence and spread of ACT resistance. In addition to pfk13, SNPs in the P. falciparum actin-binding protein coronin (pfcoronin) gene (G50E, R100K, and E107V) have recently been identified to confer reduced in vitro sensitivity to artemisinin [19]. Whilst these mutations have yet to be found in vivo in samples from Africa or elsewhere [20], it has been suggested that pfcoronin mutants could emerge as a non-pfk13 type of artemisinin resistance in natural settings [19]. Moreover, polymorphisms in the P. falciparum multidrug resistance 1 (pfmdr1) and P. falciparum chloroquine resistance transporter (pfcrt) genes have been associated with decreased susceptibility to chloroquine, and important ACT partner drugs including lumefantrine, mefloquine, and amodiaquine [21-27].

After establishment of chloroquine resistance in Pakistan, WHO recommended AS + SP for treatment of uncomplicated P. falciparum infections in 2007. However, after rapid increases in AS + SP treatment failure rates in Somalia and Sudan (ranging from 12-22\%) [1, 4], and the recent reports from India [17, 18], the national treatment guidelines were updated in 2017 with artemether-lumefantrine (AL) given together with a single low dose of primaquine as recommended first-line treatment for uncomplicated $P$. falciparum malaria [1].

This study aims to provide an update on the current prevalence of molecular markers associated with drug resistance after introduction of $A L$ as first line treatment, in the four provinces with the highest malaria burden in Pakistan. This includes a first baseline assessment of polymorphisms in the pfcoronin gene and prevalence of SNPs in the pfk13 propeller region, that have been associated with reduced sensitivity to artemisinin, as well as the proportions of infections harbouring the pfmdr1 N86, 184F, D1246 and pfcrt K76 alleles that have been associated with reduced sensitivity to lumefantrine $[25,28-36]$.

\section{Materials And Methods}

\section{Study sites}


Seventeen government and private hospitals in the four provinces with the highest malaria burden in Pakistan (Khyber Pakhtunkhwa (KPK), Sindh, Balochistan, and Punjab) were invited to provide blood samples during routine malaria surveillance. Ten facilities responded and were included in this study: Bannu, Kohat, Karak, Dera Ismail Khan, Frontier Region (FR) Khyber, FR Dera Ismaeel (DI) Khan, and Hangu in KPK province; Karachi in Sindh Province; Quetta in Balochistan Province; and Dera Ghazi Khan in Punjab Province (Fig. 1). Symptomatic, febrile patients who visited government and/or private hospitals in these selected sites between January 2018 and February 2019 were registered in this study. Written informed consent was obtained from all participants/guardians before collecting clinical history and venous blood samples.

\section{Samples storage and DNA extraction}

Approximately $5 \mathrm{ml}$ of whole blood was collected in EDTA tubes from 209 patients with malaria infections confirmed by rapid diagnostic test and/or microscopy. DNA was extracted from $200 \mu \mathrm{l}$ of whole blood using the QIAamp DNA mini kit (QIAGEN, Inc., Germany), following the manufacturer's guidelines. Extracted DNA was stored at $-20^{\circ} \mathrm{C}$ for subsequent molecular analysis.

Sequencing of the pfk13 propeller domain and pfcoronin

The 849 base pair fragment covering amino acid positions 407-689 in the pfk13-propeller domain was amplified with Q5 high-fidelity polymerase (New England Biolabs, UK) using a previously described nested polymerase chain reaction (PCR) protocol [9]. A P. falciparum 3D7 positive control and a no template control was included in each PCR. Amplified PCR products were separated by electrophoresis in 1.5\% agarose gels stained with GelRed $\circledast$ (Biotium, USA). The 849-base pair fragment was extracted from the gel and purified using GeneJET Gel Extraction Kit (Thermo Fisher Scientific, Lithuania). The purified PCR products from clinical isolates and 3D7 positive control were sent for bidirectional Sanger sequencing at Macrogen, Netherlands. The sequencing data was analysed using Sequencher version 5.1 software (Gene Codes Corporation, USA). Generated sequences were aligned with the reference sequence of 3D7 (PlasmoDB gene ID: PF3D7_1343700). Nested PCR and sequencing were repeated in case of poor-quality sequencing output.

A 368 base pair fragment covering the region in the N-terminal WD40 domain of pfcoronin where all three SNPs associated with artemisinin resistance were reported [19], was amplified in a nested PCR. The following primers were used for the primary PCR: Pfcoronin-1st_fwd 5'-TGATTTGTTCATATTATAGGTAC-3' and Pfcoronin-1st_rev 5'-TATTCTGACAAGTTCCACTTAATA-3', and for the nested PCR: Pfcoronin-nest_fwd 5'CATATTATAGGTACCATGGCAAGTT-3' and Pfcoronin-nest_rev 5'- AGGCTTTCTTCTCATTTTCTATATC - 3'. For the primary PCR, $1 \mu$ l of DNA was amplified with $1 \mu \mathrm{M}$ of each primer, $0.2 \mathrm{mM}$ dNTP, $3.75 \mathrm{mM} \mathrm{MgCl} 2,1 \mathrm{x}$ GoTaq reaction buffer, and $0.75 \mathrm{U}$ GoTaq ${ }^{\circledR}$ DNA polymerase (Promega, USA), using the following cycling program: $30 \mathrm{~s}$ at $90^{\circ} \mathrm{C}$; followed by 30 cycles of $20 \mathrm{~s}$ at $90^{\circ} \mathrm{C}, 30 \mathrm{~s}$ at $45^{\circ} \mathrm{C}, 1.30 \mathrm{~min}$ at $68^{\circ} \mathrm{C}$. For the nested PCR, $1 \mu \mathrm{L}$ of primary PCR products were amplified under the same conditions using the following cycling program: $30 \mathrm{~s}$ at $90^{\circ} \mathrm{C}$; followed by 45 cycles of $15 \mathrm{~s}$ at $94^{\circ} \mathrm{C}, 30 \mathrm{~s}$ at $50^{\circ} \mathrm{C}, 1 \mathrm{~min}$ at $68^{\circ} \mathrm{C}$. A 3D7 positive control and a no template control was included in each PCR. The nested PCR products were sent for direct bidirectional Sanger sequencing at Macrogen and analysed as described above with 3D7 as a reference (PlasmoDB gene ID: PF3D7_1251200). 
SNPs at positions pfmdr1 N86Y, Y184F, and D1246Y and pfcrt K76T were genotyped following nested PCRrestriction fragment length polymorphism (RFLP) protocols as summarized in [37]. Laboratory clones 3D7, Dd2, and $7 G 8$ were included as positive and negative restriction controls, and a no template control was included in each PCR. $5 \mu \mathrm{L}$ of each PCR amplicon was digested overnight with either Apol, $\mathrm{MluCl}$ or EcoV (New England Biolabs, UK), following manufacturer's instructions. RFLP products were run on 2-2.5\% agarose gels stained with GelRed ${ }^{\circledR}$ (Biotium, USA) and documented with a GelDoc ${ }^{\mathrm{TM}}$ system.

\section{Data analysis}

The prevalence of each SNP was defined as the proportion of isolates containing the allele of interest, including mixed infections. Isolates containing mixed SNP results at more than one position were excluded from the pfmdr1 haplotype analysis; frequencies for haplotypes were otherwise calculated as for the SNPs.

\section{Results}

Study population

In total, 209 uncomplicated P. falciparum cases from 10 different sites across the country were enrolled in this study between January 2018 and February 2019 (Table 1). Among rapid diagnostic rest and/or microscopy positive malarial isolates, 179 samples were confirmed as P. falciparum infections by PCR. Among the 179 PCR confirmed patients, 120 (67\%) were male and 59 (33\%) were female, with ages ranging from two to 65 years, and a median age of 25 years. 
Table 1

Plasmodium falciparum samples collected from 10 sites in Pakistan, 2018-2019.

\begin{tabular}{|c|c|c|c|c|}
\hline Province & City & $\begin{array}{l}\text { PCR-confirmed } \\
\text { P. falciparum } \\
\text { infection } \\
\text { (N) }\end{array}$ & $\begin{array}{l}\text { Sex } \\
\text { (\% male / \% } \\
\text { female) }\end{array}$ & $\begin{array}{l}\text { Median age } \\
\text { (years } \\
{\left[\mathrm{IQR}^{1}\right] \text { ) }}\end{array}$ \\
\hline \multirow{7}{*}{$\begin{array}{l}\text { Khyber } \\
\text { Pakhtunkhwa }\end{array}$} & Karak & 10 & $60 / 40$ & 35 [10-45] \\
\hline & Kohat & 8 & $50 / 50$ & 22 [14-28] \\
\hline & $\begin{array}{l}\text { Dera Ismeel } \\
\text { Khan }\end{array}$ & 10 & $90 / 10$ & $25[16-30]$ \\
\hline & Bannu & 13 & $85 / 15$ & $25[7-36]$ \\
\hline & Hangu & 5 & $40 / 60$ & 25 [20-35] \\
\hline & FR Khyber & 10 & $80 / 20$ & 8 [4-20] \\
\hline & FR DI Khan & 12 & $83 / 17$ & 13 [9-29] \\
\hline Punjab & Dera Ghazi Khan & 53 & $60 / 40$ & $30[15-40]$ \\
\hline Sindh & Karachi & 41 & $60 / 40$ & $25[15-37]$ \\
\hline Baluchistan & Quetta & 17 & $76 / 24$ & 28 [21-40] \\
\hline Total & & 179 & $68 / 32$ & $25[2-60]$ \\
\hline
\end{tabular}

Prevalence of SNPs in pfk13 and pfcoronin

PCR success rates for the nested PCR amplifying the pfk 13 propeller domain and pfcoronin were $97.7 \%$ (175/179) and 100\% (179/179), respectively, of which $121(69.1 \%)$ and 149 (83.2\%) generated good quality sequences. No artemisinin resistance associated SNPs were identified in either of the analysed fragments, hence all successfully sequenced samples showed wild-type genotypes in both pfk 13 and pfcoronin.

Prevalence of SNPs in pfcrt and pfmdr1

PCR success rates for the nested PCR for determining SNPs in pfmdr1 N86Y and pfcrt K76T were 100\% (179/179); PCR success rates for pfmdr1 Y184F and D1246Y were 96.1\% (172/179) and 96.6\% (173/179), respectively (Table 2). The pfmdr1 N86, 184F, D1246 and pfcrt K76 alleles that have been associated with reduced sensitivity to lumefantrine were present in $83.8 \%$ (150/179), $16.9 \%(29 / 172), 100.0 \%(173 / 173)$, and $8.4 \%(15 / 179)$ of all infections, respectively, with similar distribution across the four districts (Fig. 2). The most common pfmdr1 haplotype was NYD present in $72.9 \%$ (121/166) of the samples, followed by pfmdr1 YYD in $22.9 \%$ (38/166), and pfmdr1 NFD in 15.1\% (25/166) of the samples. The pfcrt 76T allele that is associated with chloroquine resistance was found in $98.3 \%$ (176/179) of the samples. 
Table 2

Prevalence of SNPs in pfk13, pfcoronin, pfcrt, and pfmdr1 in Pakistan, 2018-2019.

\begin{tabular}{|c|c|c|c|c|}
\hline Gene & $\mathbf{N}$ & Wild Type ${ }^{1}$ N (\%) & Mutant $^{2} \mathrm{~N}(\%)$ & Mixed $^{3} \mathrm{~N}(\%)$ \\
\hline Pfk13 & 121 & $121(100)$ & $0(0)$ & $0(0)$ \\
\hline Pfcoronin & 149 & $149(100)$ & $0(0)$ & $0(0)$ \\
\hline Pfmdr1 N86Y & 179 & $137(76.5)$ & $29(16.2)$ & $13(7.3)$ \\
\hline Pfmdr1 Y184F & 172 & $143(83.1)$ & $18(10.4)$ & $11(6.4)$ \\
\hline Pfmdr1 D1246Y & 173 & $173(100)$ & $0(0)$ & $0(0)$ \\
\hline Pfcrt K76T & 179 & $3(1.7)$ & 164 (91.2) & $12(6.7)$ \\
\hline \multicolumn{5}{|c|}{${ }^{1}$ Wild type alleles include Pfmdr1 N86, Y184, D1246, and Pfcrt K76. } \\
\hline \multicolumn{5}{|c|}{${ }^{2}$ Mutant alleles include Pfmdr1 86Y, 184F, $1246 \mathrm{Y}$, and Pfcrt $76 \mathrm{~T}}$. \\
\hline
\end{tabular}

\section{Discussion}

Pakistan has set a target to reduce the malaria burden by $75 \%$ in high endemic districts and to eliminate malaria in low endemic districts by 2020 [2]. However, if artemisinin resistance continues to spread westward from neighbouring regions in South East Asia, then efforts in further controlling and eliminating malaria will be largely hampered [38]. Early surveillance of antimalarial drug resistance through molecular epidemiology studies, is in such, essential for achieving these targets. This study provides an update on the current prevalence of molecular markers associated with drug resistance in Pakistan after the introduction of $A L$ as first-line treatment in 2017, including a first baseline assessment of polymorphisms in the pfcoronin gene which has been associated with decreased in vitro sensitivity to artemisinin.

No SNPs associated with artemisinin resistance were observed in the pfk13 propeller domain, nor in pfcoronin. One other study has to date, assessed the prevalence of polymorphisms in pfk13 in Pakistan [39]. This study reported nine non-synonymous and four synonymous mutations among 209 samples collected in 2016-2017. None of these SNPs correspond to mutations that have been associated with artemisinin resistance. These findings are in line with in vivo assessments of ACT efficacy in Pakistan. There has been no evidence of reduced ACT efficacy in Pakistan as of yet, with adequate clinical and parasitological responses of greater than $98 \%$ after treatment with $A S+S P, A L$, and dihydroartemisinin-piperaquine [40]. However, the recent increase in AS + SP treatment failures in the North Eastern states of India, bordering with Myanmar, is a matter of concern for the continued westward spread of ACT resistance across from Southeast Asia [17]. Especially since molecular data have indicated that resistance to the SP partner drug is being established in Pakistan, although mutations that confer a high risk of SP treatment failure are still rare or non-existent $[39,40]$. 
$\mathrm{AL}$, on the other hand, remains efficacious in the North Eastern region of the India [41, 42], and is currently the recommended first line treatment for P. falciparum in the whole of the WHO Eastern Mediterranean Region, covering Afghanistan, Djibouti, Pakistan, Somalia and Sudan [1]. The efficacy of AL has been monitored in each of these countries, except in Djibouti. All therapeutic efficacy studies in these countries have showed low rates $(<5 \%)$ of AL treatment failure, supporting its continued use as first-line treatment. However, whilst no SNPs associated with artemisinin resistance were observed in pfk13 and pfcoronin, the pfmdr1 N86 and D1246 alleles which have been associated with reduced sensitivity to lumefantrine [25, 2836] were present in $83.8 \%$ and $100 \%$ of the isolates, respectively (Table 2). The pfmdr1 N86 allele in particular, as well as increased pfmdr1 copy number, have shown to be significant independent risk factors for recrudescence in patients treated with AL [36]. The prevalence of pfmdr1 N86 has increased since the introduction of ACTs in Pakistan in 2007, with prevalence's ranging from 55-67\% in 2005-2007, and $96 \%$ in 2011, (Table 3) [43-45]. The pfmdr1 D1246 has been consistently reported in 100\% of isolates since 2007. Pfmdr1 copy number was not analysed in this study due to its previously reported very low or non-existent presence in Pakistan. 
Table 3

Prevalence of polymorphisms in pfmdr1 and pfcrt before introduction of AL in Pakistan.

\begin{tabular}{|c|c|c|c|c|}
\hline & $\begin{array}{l}2005-2007(N= \\
240) \\
{[43]}\end{array}$ & $\begin{array}{l}2007(\mathrm{~N}=28) \\
{[44]}\end{array}$ & $\begin{array}{l}2011(\mathrm{~N}= \\
171) \\
{[45]}\end{array}$ & $\begin{array}{l}2018-2019(\mathrm{~N}=179) \\
\text { [current study] }\end{array}$ \\
\hline \multicolumn{5}{|l|}{ Pfmdr1 N86Y } \\
\hline N86 & $43 \%$ & $67 \%$ & $80 \%$ & $77 \%$ \\
\hline $86 Y$ & $45 \%$ & $33 \% 1$ & $4 \%$ & $16 \%$ \\
\hline N86Y (mixed) & $12 \%$ & Not stated ${ }^{1}$ & $16 \%$ & $7 \%$ \\
\hline \multicolumn{5}{|l|}{ Pfmdr1 Y184F } \\
\hline Y184 & ND & ND & $75 \%$ & $83 \%$ \\
\hline $184 \mathrm{~F}$ & ND & ND & $0 \%$ & $10 \%$ \\
\hline Y184F (mixed) & ND & ND & $25 \%$ & $6 \%$ \\
\hline \multicolumn{5}{|l|}{ Pfmdr1 D1246Y } \\
\hline D1246 & ND & $100 \%$ & $100 \%$ & $100 \%$ \\
\hline $1246 Y$ & ND & $0 \%$ & $0 \%$ & $0 \%$ \\
\hline $\begin{array}{l}\text { D1246Y } \\
\text { (mixed) }\end{array}$ & ND & $0 \%$ & $0 \%$ & $0 \%$ \\
\hline \multicolumn{5}{|l|}{ Pfmdr1 CNV } \\
\hline Single copy & ND & $\begin{array}{l}99.6 \% \\
(232 / 233)^{2}\end{array}$ & $100 \%$ & ND \\
\hline
\end{tabular}

${ }^{1}$ Proportion of infections containing pfmdr1 86Y, proportion of which were mixed infections not stated.

2 ( $n$ /number of samples successfully analysed)

$\mathrm{ND}=$ not determined $; \mathrm{CNV}=$ copy number variation 


\begin{tabular}{|c|c|c|c|c|}
\hline & $\begin{array}{l}2005-2007(N= \\
240) \\
{[43]}\end{array}$ & $\begin{array}{l}2007(N=28) \\
{[44]}\end{array}$ & $\begin{array}{l}2011(\mathrm{~N}= \\
171) \\
{[45]}\end{array}$ & $\begin{array}{l}2018-2019(\mathrm{~N}=179) \\
\text { [current study] }\end{array}$ \\
\hline Multiple copy & ND & $0.4 \%(1 / 233)^{2}$ & $0 \%$ & ND \\
\hline \multicolumn{5}{|l|}{ Pfcrt K76T } \\
\hline K76 & $7 \%$ & $0 \%$ & $0 \%$ & $2 \%$ \\
\hline $76 \mathrm{~T}$ & $93 \%$ & $100 \%$ & $100 \%$ & $91 \%$ \\
\hline K76T (mixed) & $0 \%$ & $0 \%$ & $0 \%$ & $07 \%$ \\
\hline \multicolumn{5}{|c|}{${ }^{1}$ Proportion of infections containing pfmdr1 86Y, proportion of which were mixed infections not stated. } \\
\hline \multicolumn{5}{|c|}{2 (n/number of samples successfully analysed) } \\
\hline \multicolumn{5}{|c|}{$N D=$ not determined; $C N V=$ copy number variation } \\
\hline
\end{tabular}

Over a decade of wide-scale use of AL, mainly in African counties, has selected for pfcrt K76 and the pfmdr1 haplotype N86/184F/D1246, with a parallel decline in pfcrt 76T and the pfmdr1 86Y/Y184/1246Y haplotype $[31,33,35,46-49]$. Parasites harbouring the pfmdr1 NFD haplotype have shown to able to re-infect patients whose lumefantrine blood concentrations were 15-fold higher than for parasites carrying the pfmdr1 YYY haplotype [32]. Despite this wide scale selection of SNPs associated with reduced sensitivity of lumefantrine, AL remains highly effective across sub-Saharan Africa [50]. However, tracking changes in prevalences of molecular markers of drug resistance can be a sensitive indicator of the selection of parasite populations, and may signal early decreases in drug susceptibility. In addition, decreasing efficacy of the partner drug may expose the artemisinin component of the ACT to selective pressure, and could facilitate emergence of new foci of resistance to artemisinin, as observed in the Greater Mekong Subregion [36]. Hence, in addition to therapeutic efficacy studies, further monitoring of the selection of molecular markers associated with both artemether and lumefantrine resistance in Pakistan, as in this study, is considered to be a critical tool to detect and prevent the spread of artemisinin resistance, and for preserving the efficacy of AL in the area [36].

Finally, the observed high prevalence $(98.3 \%)$ of the chloroquine resistance associated pfcrt $76 \mathrm{~T}$ allele is in line with previous assessments [43-45, 51,52], and provides molecular evidence of chloroquine resistant $P$. falciparum in Pakistan. Although chloroquine was removed from the national guidelines for treatment of $P$. falciparum malaria more than ten years ago, chloroquine is still the recommended in the treatment of $P$. vivax and unconfirmed malaria infections [1]. Improper diagnosis of malaria, due to presumptive diagnosis based on clinical grounds and/or lack of diagnostic facilities (which are common practices in resourcelimited countries such as Pakistan), is likely to sustain a high exposure of P. falciparum to chloroquine, maintaining the near fixation of the chloroquine resistant pfcrt 76T allele.

\section{Conclusions}


This study provides an update on the current prevalence of molecular markers associated with reduced sensitivity to artemether and/or lumefantrine in Pakistan. No mutations associated with artemisinin resistance were observed in pfk13 or pfcoronin. However, the prevalence of the pfmdr1 N86 and D1246 alleles, that have been associated with decreased susceptibility to lumefantrine, remain high. Although clinical and molecular data suggest that the current malaria treatment guideline for $P$. falciparum are presently effective, close monitoring for artemisinin and lumefantrine resistance will be critical to ensure early detection and enhanced containment of emerging ACT resistance spreading across from Southeast Asia.

\section{List Of Abreviations}

ACT Artemisinin-based combination therapy

AL Artemether-lumefantrine

AS+SP Artesunate-sulfadoxine-pyrimethamine

DI Dera Ismail

DNA Deoxyribonucleic acid

FR Frontier region

KPK Khyber Pakhtunkhwa

PCR Polymerase chain reaction

Pfcoronin Plasmodium falciparum coronin gene

Pfcrt Plasmodium falciparum chloroquine resistance transporter gene

Pfk13 Plasmodium falciparum Kelch 13 gene

Pfmdr1 Plasmodium falciparum multi drug resistance 1 gene

RFLP Restriction fragment length polymorphism

SNP Single nucleotide polymorphism

WHO World health organization

\section{Declarations}

Ethics approval and consent to participate: Ethical approval for collecting human blood samples in this study was granted by the Research Ethical Committee (REC) of Kohat University of Science and Technology (KUST), Khyber Pakhtunkhwa, Pakistan [Ref. No. KUST/Ethical Committee/18-04]. Written informed consent 
was obtained from all participants/guardians before obtaining clinical history and blood samples. Ethical approval for molecular work at Karolinska Institutet was granted by the Regional Ethics Committee in Stockholm, Sweden [2016/2286-32].

Consent for publication: Not applicable.

Availability of data and materials: The datasets used and/or analysed during the current study are available from the corresponding author on reasonable request.

Competing interests: The authors declare that they have no competing interests.

Funding: This work, as well as AQK doctoral studies, was supported by an International Research Support Initiative Program (IRSIP) grant [grant number: IRSIP-42 BMS-24] sponsored by the Higher Education Commission (HEC), Islamabad, Pakistan. The molecular analyses conducted at Karolinska Institutet Stockholm, Sweden were supported in part by the Swedish Research Council (VR) [grant number: 201705644] and KI Foundation and Funds [grant number: 2018-01515].

Authors' contributions: AQK, MH, AAK, TAK, and FM designed the collection of samples in the field. AQK, LP, $\mathrm{SL}, \mathrm{BS}$, and UM designed and conducted the molecular analyses. AQK, LP, SL, and UM analysed the data. AQK and UM drafted the manuscript. All authors read and approved the final manuscript.

Acknowledgements: The authors thank Adil Shah Mufti Farees ud Din Khattak, Waqas Ahmad, Sheikh Murtaza, Muhammad Yaqoob, Fahim Ahmad Akif, Muhammad Farman, and Waheed Khan in Pakistan for help with sample collection.

\section{References}

1. World Health Organization: World malaria report. 2019.

[https://www.who.int/malaria/publications/world-malaria-report-2019/en/]. Accessed on: 17 Jan 2020.

2. Directorate of Malaria Control: Pakistan Malaria Annual Report. 2019.

[http://dmc.gov.pk/documents/pdfs/Pakistan\%20Malaria\%20Annual\%20Report\%202019\%20(002).pdf]. Accessed on: 17 Jan 2020.

3. Menard D, Dondorp A: Antimalarial drug resistance: a threat to malaria elimination. Cold Spring Harbor perspectives in medicine 2017, 7:a025619.

4. World Health Organization: Artemisinin resistance and artemisinin-based combination therapy efficacy: status report. 2018. [https://apps.who.int/iris/handle/10665/274362]. Accessed on: 17 Jan 2020.

5. Dondorp AM, Nosten F, Yi P, Das D, Phyo AP, Tarning J, Lwin KM, Ariey F, Hanpithakpong W, Lee SJ: Artemisinin resistance in Plasmodium falciparum malaria. New England Journal of Medicine 2009, 361:455-467.

6. Noedl H, Se Y, Schaecher K, Smith BL, Socheat D, Fukuda MM: Evidence of artemisinin-resistant malaria in western Cambodia. New England Journal of Medicine 2008, 359:2619-2620. 
7. Tun KM, Imwong M, Lwin KM, Win AA, Hlaing TM, Hlaing T, Lin K, Kyaw MP, Plewes K, Faiz MA: Spread of artemisinin-resistant Plasmodium falciparum in Myanmar: a cross-sectional survey of the K13 molecular marker. The Lancet infectious diseases 2015, 15:415-421.

8. Whittaker M: Update from the Asia Pacific Malaria Elimination Network (APMEN). Malaria journa/ 2012 , 11:054.

9. Ariey F, Witkowski B, Amaratunga C, Beghain J, Langlois A-C, Khim N, Kim S, Duru V, Bouchier C, Ma L: A molecular marker of artemisinin-resistant Plasmodium falciparum malaria. Nature 2014, 505:50-55.

10. Straimer J, Gnädig NF, Witkowski B, Amaratunga C, Duru V, Ramadani AP, Dacheux M, Khim N, Zhang L, Lam S: K13-propeller mutations confer artemisinin resistance in Plasmodium falciparum clinical isolates. Science 2015, 347:428-431.

11. Chenet SM, Akinyi Okoth S, Huber CS, Chandrabose J, Lucchi NW, Talundzic E, Krishnalall K, Ceron N, Musset L, Macedo de Oliveira A, et al: Independent Emergence of the Plasmodium falciparum Kelch Propeller Domain Mutant Allele C580Y in Guyana. J Infect Dis 2016, 213:1472-1475.

12. Miotto O, Sekihara M, Tachibana S-I, Yamauchi M, Pearson RD, Amato R, Gonçalves S, Somya M, Noviyanti R, Marfurt J, et al: Emergence of artemisinin-resistant <em>Plasmodium falciparum</em> with <em>kelch13</em> C580Y mutations on the island of New Guinea. 2019:621813.

13. Tacoli C, Gai PP, Bayingana C, Sifft K, Geus D, Ndoli J, Sendegeya A, Gahutu JB, Mockenhaupt FP: Artemisinin Resistance-Associated K13 Polymorphisms of Plasmodium falciparum in Southern Rwanda, 2010-2015. Am J Trop Med Hyg 2016, 95:1090-1093.

14. Amaratunga C, Lim P, Suon S, Sreng S, Mao S, Sopha C, Sam B, Dek D, Try V, Amato R: Dihydroartemisinin-piperaquine resistance in Plasmodium falciparum malaria in Cambodia: a multisite prospective cohort study. The Lancet infectious diseases 2016, 16:357-365.

15. Leang R, Taylor WR, Bouth DM, Song L, Tarning J, Char MC, Kim S, Witkowski B, Duru V, Domergue A: Evidence of Plasmodium falciparum malaria multidrug resistance to artemisinin and piperaquine in western Cambodia: dihydroartemisinin-piperaquine open-label multicenter clinical assessment. Antimicrobial agents and chemotherapy 2015, 59:4719-4726.

16. Phyo A: Declining efficacy of mefloquine-artesunate combination and relative role of drug-resistant molecular markers: Thai-Myanmar Border 2003-2013. International Journal of Infectious Diseases 2016, 45:15.

17. Das S, Saha B, Hati AK, Roy S: Evidence of artemisinin-resistant Plasmodium falciparum malaria in eastern India. New England Journal of Medicine 2018, 379:1962-1964.

18. Das S, Manna S, Saha B, Hati AK, Roy S: Novel pfkelch13 Gene Polymorphism Associates With Artemisinin Resistance in Eastern India. Clin Infect Dis 2019, 69:1144-1152.

19. Demas AR, Sharma Al, Wong W, Early AM, Redmond S, Bopp S, Neafsey DE, Volkman SK, Hartl DL, Wirth DF: Mutations in Plasmodium falciparum actin-binding protein coronin confer reduced artemisinin susceptibility. Proceedings of the National Academy of Sciences 2018, 115:12799-12804.

20. Velavan TP, Nderu D, Agbenyega T, Ntoumi F, Kremsner PG: An alternative dogma on reduced artemisinin susceptibility: A new shadow from east to west. Proceedings of the National Academy of Sciences 2019, 116:12611-12612. 
21. Holmgren G, Hamrin J, Svärd J, Mårtensson A, Gil JP, Björkman A: Selection of pfmdr1 mutations after amodiaquine monotherapy and amodiaquine plus artemisinin combination therapy in East Africa. Infection, genetics and evolution 2007, 7:562-569.

22. Takala-Harrison S, Clark TG, Jacob CG, Cummings MP, Miotto O, Dondorp AM, Fukuda MM, Nosten F, Noedl $\mathrm{H}$, Imwong M: Genetic loci associated with delayed clearance of Plasmodium falciparum following artemisinin treatment in Southeast Asia. Proceedings of the National Academy of Sciences 2013, 110:240-245.

23. Price RN, Uhlemann A-C, Brockman A, McGready R, Ashley E, Phaipun L, Patel R, Laing K, Looareesuwan $\mathrm{S}$, White $\mathrm{NJ}$ : Mefloquine resistance in Plasmodium falciparum and increased pfmdr1 gene copy number. The Lancet 2004, 364:438-447.

24. Sidhu ABS, Uhlemann A-C, Valderramos SG, Valderramos J-C, Krishna S, Fidock DA: Decreasing pfmdr1 copy number in Plasmodium falciparum malaria heightens susceptibility to mefloquine, lumefantrine, halofantrine, quinine, and artemisinin. The Journal of infectious diseases 2006, 194:528-535.

25. Sisowath C, Stromberg J, Martensson A, Msellem M, Obondo C, Bjorkman A, Gil JP: In vivo selection of Plasmodium falciparum pfmdr $186 \mathrm{~N}$ coding alleles by artemether-lumefantrine (Coartem). J Infect Dis 2005, 191:1014-1017.

26. Holmgren G, Gil JP, Ferreira PM, Veiga MI, Obonyo CO, Björkman A: Amodiaquine resistant Plasmodium falciparum malaria in vivo is associated with selection of pfcrt 76T and pfmdr1 $86 \mathrm{Y}$. Infection, Genetics and Evolution 2006, 6:309-314.

27. Bray PG, Martin RE, Tilley L, Ward SA, Kirk K, Fidock DA: Defining the role of PfCRT in Plasmodium falciparum chloroquine resistance. Molecular microbiology 2005, 56:323-333.

28. Sisowath C, Ferreira PE, Bustamante LY, Dahlstrom S, Martensson A, Bjorkman A, Krishna S, Gil JP: The role of pfmdr1 in Plasmodium falciparum tolerance to artemether-lumefantrine in Africa. Trop Med Int Health 2007, 12:736-742.

29. Sisowath C, Petersen I, Veiga MI, Martensson A, Premji Z, Bjorkman A, Fidock DA, Gil JP: In vivo selection of Plasmodium falciparum parasites carrying the chloroquine-susceptible pfcrt K76 allele after treatment with artemether-lumefantrine in Africa. J Infect Dis 2009, 199:750-757.

30. Eyase FL, Akala HM, Ingasia L, Cheruiyot A, Omondi A, Okudo C, Juma D, Yeda R, Andagalu B, Wanja E, et al: The role of Pfmdr1 and Pfcrt in changing chloroquine, amodiaquine, mefloquine and lumefantrine susceptibility in western-Kenya P. falciparum samples during 2008-2011. PLoS One 2013, 8:e64299.

31. Baliraine FN, Rosenthal PJ: Prolonged selection of pfmdr1 polymorphisms after treatment of falciparum malaria with artemether-lumefantrine in Uganda. J Infect Dis 2011, 204:1120-1124.

32. Malmberg M, Ferreira PE, Tarning J, Ursing J, Ngasala B, Bjorkman A, Martensson A, Gil JP: Plasmodium falciparum drug resistance phenotype as assessed by patient antimalarial drug levels and its association with pfmdr1 polymorphisms. J Infect Dis 2013, 207:842-847.

33. Malmberg M, Ngasala B, Ferreira PE, Larsson E, Jovel I, Hjalmarsson A, Petzold M, Premji Z, Gil JP, Bjorkman A, Martensson A: Temporal trends of molecular markers associated with artemetherlumefantrine tolerance/resistance in Bagamoyo district, Tanzania. Malar J 2013, 12:103. 
34. Mwai L, Kiara SM, Abdirahman A, Pole L, Rippert A, Diriye A, Bull P, Marsh K, Borrmann S, Nzila A: In vitro activities of piperaquine, lumefantrine, and dihydroartemisinin in Kenyan Plasmodium falciparum isolates and polymorphisms in pfcrt and pfmdr1. Antimicrob Agents Chemother 2009, 53:5069-5073.

35. Thomsen TT, Madsen LB, Hansson HH, Tomas EV, Charlwood D, Bygbjerg IC, Alifrangis M: Rapid selection of Plasmodium falciparum chloroquine resistance transporter gene and multidrug resistance gene-1 haplotypes associated with past chloroquine and present artemether-lumefantrine use in Inhambane District, southern Mozambique. Am J Trop Med Hyg 2013, 88:536-541.

36. Venkatesan M, Gadalla NB, Stepniewska K, Dahal P, Nsanzabana C, Moriera C, Price RN, Martensson A, Rosenthal PJ, Dorsey G, et al: Polymorphisms in Plasmodium falciparum Chloroquine Resistance Transporter and Multidrug Resistance 1 Genes: Parasite Risk Factors that Affect Treatment Outcomes for P-falciparum Malaria after Artemether-Lumefantrine and Artesunate-Amodiaquine. American Journal of Tropical Medicine and Hygiene 2014, 91:833-843.

37. Morris U, Xu W, Msellem MI, Schwartz A, Abass A, Shakely D, Cook J, Bhattarai A, Petzold M, Greenhouse $B$, et al: Characterising temporal trends in asymptomatic Plasmodium infections and transporter polymorphisms during transition from high to low transmission in Zanzibar, 2005-2013. Infect Genet Evol 2015, 33:110-117.

38. Wongsrichanalai C, Sibley C: Fighting drug-resistant Plasmodium falciparum: the challenge of artemisinin resistance. Clinical Microbiology and Infection 2013, 19:908-916.

39. Yaqoob A, Khattak AA, Nadeem MF, Fatima H, Mbambo G, Ouattara A, Adams M, Zeeshan N, TakalaHarrison S: Prevalence of molecular markers of sulfadoxine-pyrimethamine and artemisinin resistance in Plasmodium falciparum from Pakistan. Malaria journal 2018, 17:471.

40. Kakar Q, Sheikh S, Ahmed I, Khan MA, Jamil M, ElMohammady H, Warsame M: Efficacy of artemisininbased combination therapies for the treatment of falciparum malaria in Pakistan (2007-2015): In vivo response and dhfr and dhps mutations. Acta Trop 2016, 164:17-22.

41. Bharti PK, Shukla MM, Ringwald P, Krishna S, Singh PP, Yadav A, Mishra S, Gahlot U, Malaiya JP, Kumar A: Therapeutic efficacy of artemether-lumefantrine for the treatment of uncomplicated Plasmodium falciparum malaria from three highly malarious states in India. Malaria journal 2016, 15:498.

42. Mishra N, Bharti RS, Mallick P, Singh OP, Srivastava B, Rana R, Phookan S, Gupta HP, Ringwald P, Valecha N: Emerging polymorphisms in falciparum Kelch 13 gene in Northeastern region of India. Malaria journal 2016, 15:583.

43. Ghanchi NK, Ursing J, Beg MA, Veiga MI, Jafri S, Martensson A: Prevalence of resistance associated polymorphisms in Plasmodium falciparum field isolates from southern Pakistan. Malar J 2011, $10: 18$.

44. Khatoon L, Baliraine FN, Bonizzoni M, Malik SA, Yan G: Prevalence of antimalarial drug resistance mutations in Plasmodium vivax and P. falciparum from a malaria-endemic area of Pakistan. Am J Trop Med Hyg 2009, 81:525-528.

45. Khattak AA, Venkatesan M, Jacob CG, Artimovich EM, Nadeem MF, Nighat F, Hombhanje F, Mita T, Malik SA, Plowe CV: A comprehensive survey of polymorphisms conferring anti-malarial resistance in Plasmodium falciparum across Pakistan. Malar J 2013, 12:300. 
46. Kavishe RA, Paulo P, Kaaya RD, Kalinga A, van Zwetselaar M, Chilongola J, Roper C, Alifrangis M: Surveillance of artemether-lumefantrine associated Plasmodium falciparum multidrug resistance protein-1 gene polymorphisms in Tanzania. Malaria journal 2014, 13:264.

47. Thomsen TT, Ishengoma DS, Mmbando BP, Lusingu JP, Vestergaard LS, Theander TG, Lemnge MM, Bygbjerg IC, Alifrangis M: Prevalence of single nucleotide polymorphisms in the Plasmodium falciparum multidrug resistance gene (Pfmdr-1) in Korogwe District in Tanzania before and after introduction of artemisinin-based combination therapy. Am J Trop Med Hyg 2011, 85:979-983.

48. Yeka A, Kigozi R, Conrad MD, Lugemwa M, Okui P, Katureebe C, Belay K, Kapella BK, Chang MA, Kamya MR: Artesunate/amodiaquine versus artemether/lumefantrine for the treatment of uncomplicated malaria in Uganda: a randomized trial. The Journal of infectious diseases 2016, 213:1134-1142.

49. Venkatesan M, Gadalla NB, Stepniewska K, Dahal P, Nsanzabana C, Moriera C, Price RN, Martensson A, Rosenthal PJ, Dorsey G, et al: Polymorphisms in Plasmodium falciparum chloroquine resistance transporter and multidrug resistance 1 genes: parasite risk factors that affect treatment outcomes for $P$. falciparum malaria after artemether-lumefantrine and artesunate-amodiaquine. Am J Trop Med Hyg 2014, 91:833-843.

50. Conrad MD, Rosenthal PJ: Antimalarial drug resistance in Africa: the calm before the storm? Lancet Infect Dis 2019, 19:e338-e351.

51. Sahar S, Tanveer A, Ali A, Bilal H, Muhammad Saleem R: Pfcrt Gene in Plasmodium falciparum Field Isolates from Muzaffargarh, Pakistan. J Arthropod Borne Dis 2015, 9:204-214.

52. Rawasia WF, Sridaran S, Patel JC, Abdallah J, Ghanchi NK, Barnwell JW, Escalante AA, Udhayakumar V, Beg MA: Genetic backgrounds of the Plasmodium falciparum chloroquine resistant transporter (pfcrt) alleles in Pakistan. Infection, Genetics and Evolution 2012, 12:278-281.

\section{Figures}




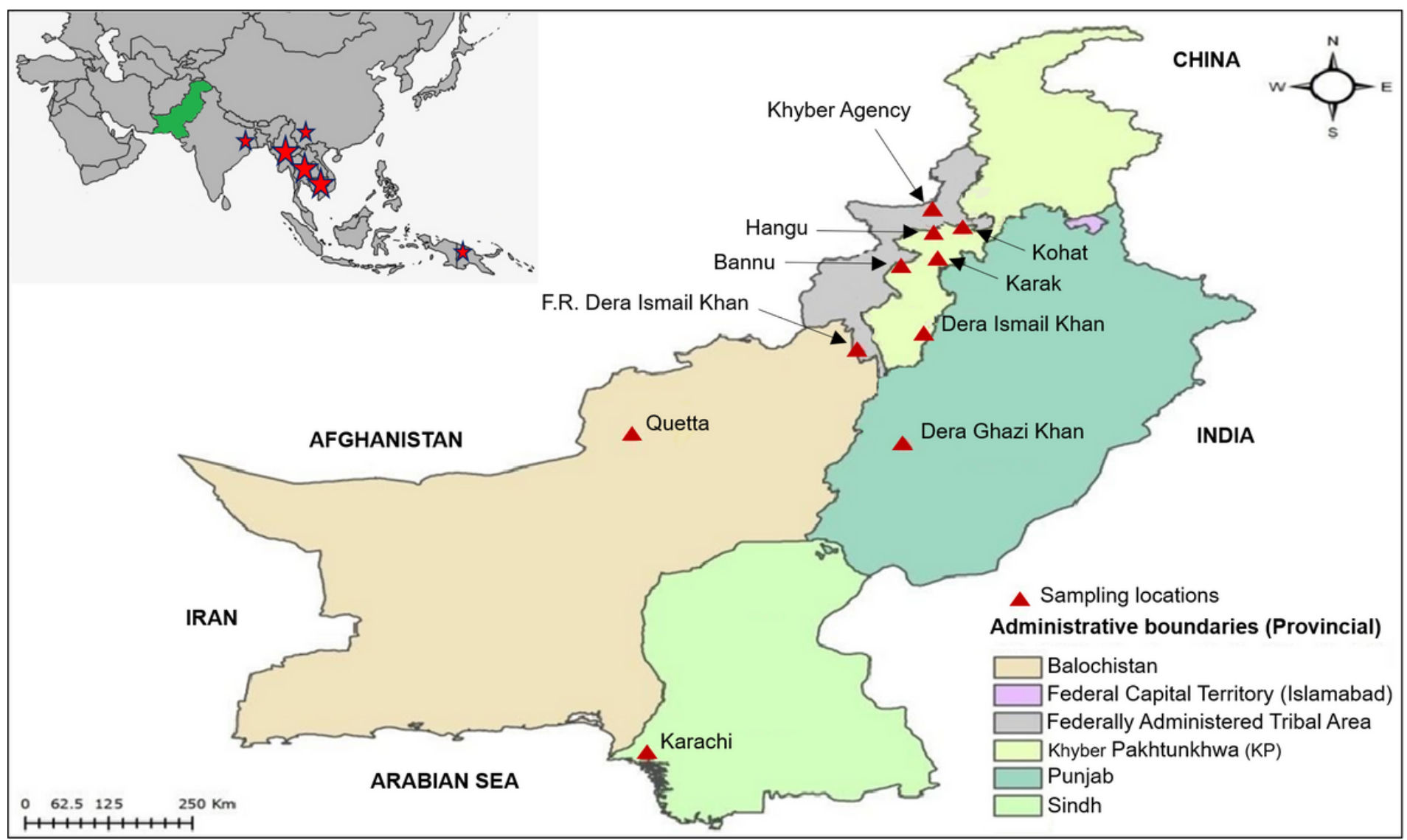

Figure 1

Map of Pakistan showing geographical location of 10 different sample collection sites. Pakistan is highlighted in green in the top left panel; red stars identify locations of reported Artemisinin resistance. In the enlarged map of Pakistan, red triangles indicate the 10 different sample collection sites in four provinces. 


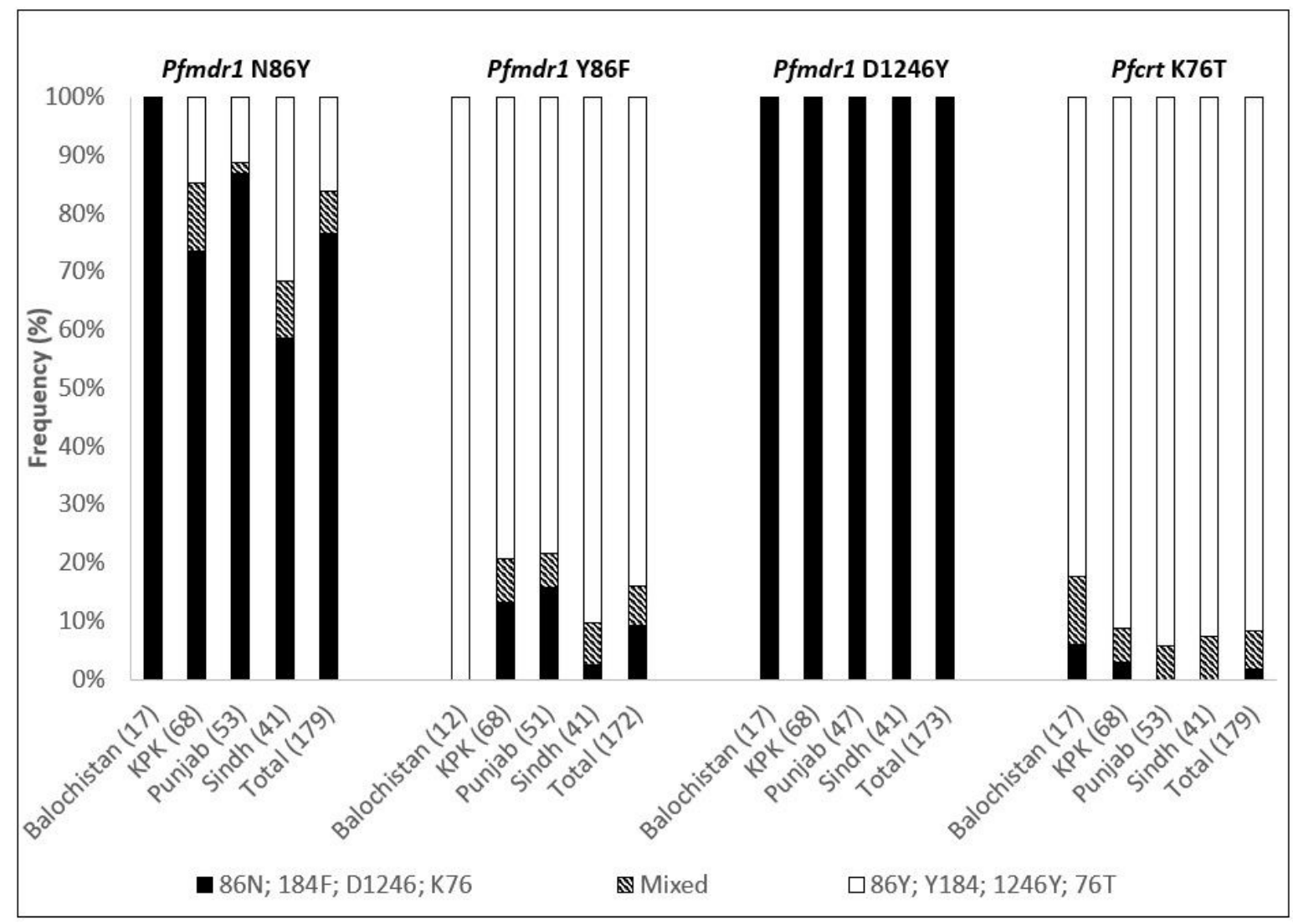

Figure 2

Distribution of molecular markers of drug resistance across four provinces of Pakistan, 2018-2019. Clustered, stacked bar chart showing the prevalence of single nucleotide polymorphisms associated with drug resistance in pfmdr1 and pfcrt. Black and striped bars show the frequency of infections carrying alleles associated with reduced sensitivity to lumefantrine i.e., pfmdr1 N86, 184F, D1246, and pfcrt K76. The number of samples genotyped is shown in brackets. 